\title{
Challenges of Endoscopic Management of Pancreaticobiliary Complications in Surgically Altered Gastrointestinal Anatomy
}

\author{
Tin Moe Wai and Eun Young Kim² \\ ${ }^{1}$ Department of Gastroenterology, Yangon General Hospital, University of Medicine (1), Yangon, Myanmar, ${ }^{2}$ Division of Gastroenterology, \\ Department of Internal Medicine, Catholic University of Daegu School of Medicine, Daegu, Korea
}

Pancreaticobiliary complications following various surgical procedures, including liver transplantation, are not uncommon and are important causes of morbidity and mortality. Therapeutic endoscopy plays a substantial role in these patients and can help to avoid the need for reoperation. However, the endoscopic approach in patients with surgically altered gastrointestinal (GI) anatomy is technically challenging because of the difficulty in entering the enteral limb to reach the target orifice to manage pancreaticobiliary complications. Additional procedural complexity is due to the need of special devices and accessories to obtain successful cannulation and absence of an elevator in forward-viewing endoscopes, which is frequently used in this situation. Once bilioenteric anastomosis is reached, the technical success rates achieved in expert hands approach those of patients with intact GI anatomy. The success of endoscopic therapy in patients with surgically altered GI anatomy depends on multiple factors, including the expertise of the endoscopist, understanding of postoperative anatomic changes, and the availability of suitable scopes and accessories for endoscopic management. In this issue of Clinical Endoscopy, the focused review series deals with pancreatobiliary endoscopy in altered GI anatomy such as bilioenteric anastomosis and post-gastrectomy. Clin Endosc 2016;49:502-505

Key Words: Pancreaticobiliary complications; Challenge; Endotherapy; Altered anatomy

\section{INTRODUCTION}

Pancreaticobiliary complications following various pancreatic and hepatic operations were previously treated conventionally with surgery, but reoperations in such patients who are critically ill are often difficult because of inflammation, infections, and adhesions. Although endoscopic therapy can help avoid huge amounts of reoperation, it tends to be technically challenging especially in cases of altered gastrointestinal (GI) anatomy. The systematic approach for the use of endoscopic retrograde cholangiopancreatography (ERCP) or endoscopic ultrasonography (EUS) as a treatment modal-

Received: September 2, 2016 Accepted: September 4, 2016

Correspondence: Eun Young Kim

Division of Gastroenterology, Department of Internal Medicine, Catholic University of Daegu School of Medicine, 33 Duryugongwon-ro 17-gil, Nam-gu, Daegu 42472, Korea

Tel: +82-53-650-4092, Fax: +82-53-624-3281, E-mail: kimey@cu.ac.kr

(cc) This is an Open Access article distributed under the terms of the Creative Commons Attribution Non-Commercial License (http://creativecommons.org/ licenses/by-nc/3.0) which permits unrestricted non-commercial use, distribution, and reproduction in any medium, provided the original work is properly cited. ity for treatment of pancreaticobiliary adverse events after surgery has not been clearly established because of the rarity of data. This review focused on challenges encountered by endoscopists in managing pancreaticobiliary complications in surgically altered GI anatomy based on the published articles of highly experienced groups.

\section{PANCREATICOBILIARY COMPLICATIONS AFTER GI SURGERY}

Pancreatic leaks can occur in about $20 \%$ of cases following Whipple surgery (pancreaticoduodenectomy), ${ }^{1}$ whereas the pancreatic fistula rate was $5 \%$ for chronic pancreatitis, $12 \%$ for pancreatic cancer, $15 \%$ for ampullary cancer, and 33\% for bile duct cancer in a large case review of 2,664 patients who underwent pancreaticoduodenectomy. ${ }^{2}$ Endoscopy plays a limited role in the management of acute postoperative adverse events (pancreatic duct [PD] leak, bile leak, and pancreatic fistula) following Whipple surgery. Pancreatic leaks can be 
managed by percutaneous drainage, administration of octreotide, and intravenous hyperalimentation. ${ }^{1}$ However, endoscopy plays a significant role in the management of retained surgically placed pancreatic stents, recurrence of malignancy, and delayed pancreaticobiliary (choledochojejunostomy and pancreaticojejunostomy) strictures and/or stones. ${ }^{1}$ Bilioenteric stricture was observed after pancreaticoduodenectomy in 2.6\% of the patients. ${ }^{3}$ Roux-en-Y hepaticojejunostomy is performed with various indications, including recurrent biliary stones, benign distal biliary stricture, cholangiocarcinoma, choledochal cyst, and liver transplantation. Post-liver transplantation biliary adverse events occur in up to $20 \%$ of patients and are important causes of early and late postoperative morbidity and mortality. The most common biliary adverse events are strictures, leaks, stones, and sphincter of Oddi dysfunction. ${ }^{5}$ Endoscopic management of these adverse events is greatly influenced by the type of biliary reconstruction during liver transplantation. In cases of anastomotic biliary strictures that occur in about $5 \%-10 \%$ of liver transplantation recipients within 1 year after surgery, endoscopic managements are mostly successful. ${ }^{6}$

\section{CHALLENGING POSTSURGICAL ALTERED GI ANATOMY FOR ENDOSCOPIC THERAPY}

Endoscopists frequently come across patients with postoperative altered anatomy such as in Billroth II gastrectomy, pancreaticoduodenectomy (classic or pylorus-preserving pancreaticoduodenectomy), Roux-en-Y gastric bypass (RYGB), Roux-en-Y hepaticojejunostomy, and Roux-en-Y choledochojejunostomy. Challenges encountered by endoscopists in these altered GI anatomy are usually due to difficulty in (1) identifying the pancreaticobiliary enteral limb; (2) reaching and identifying the major papilla or pancreaticoenteric and/or bilioenteric anastomoses; (3) selective cannulation of the bile or PD from an altered orientation; and (4) performing therapeutic interventions with devices designed for standard ERCP or possibly with a forward-viewing endoscope that is not equipped with an elevator. To correctly identify the enteral limbs, understanding the postoperative anatomic change and length of surgically created pancreaticobiliary limb is important. Based on this information, the adequate endoscopes and suitable accessories can be chosen to successfully accomplish the aim of the endoscopic procedures.

\section{Pancreaticoduodenectomy (Classic and pylorus- pre- serving Whipple procedure)}

In patients with relatively short afferent limbs, ERCP may be performed with a duodenoscope, forward-viewing gastroscope, or colonoscope (adult and pediatric). However, the success rate in accessing the pancreatic anastomosis is suboptimal with a standard duodenoscope. ${ }^{8}$ Absence of an elevator in a colonoscope makes it challenging to maneuver the accessories and accomplish therapeutic interventions. A prototype oblique-viewing endoscope with an elevator has been used to circumvent this drawback. ${ }^{1}$ Limited but increasing amount of data are available about overtube-assisted enteroscopy ERCP with a single-balloon enteroscope (SBE) ${ }^{4,9}$ or double-balloon enteroscope $(\mathrm{DBE})^{10}$ to get technical success in case of failure to reach the anastomotic site with standard endoscopes. Other endoscopic options to access the biliary tree is combined use of interventional radiology and ERCP in which the placement of a stent or guide wire by an interventional radiologist was followed by subsequent endoscopic management. Percutaneous approach to reach pancreaticojejunal anastomotic strictures has been used at tertiary centers when pancreatic anastomosis cannot be identified or accessed endoscopically. ${ }^{11}$ This combined approach is preceded by a detailed cross-sectional imaging such as computed tomography (CT) or magnetic resonance cholangiopancreatography (MRCP). ${ }^{12}$ Another interesting technique for failed identification or access of pancreatic anastomosis is the combined EUS and ERCP technique. Indications of EUS-guided PD drainage include chronic pancreatitis-induced strictures and stones, disconnected PDs, inaccessible ampulla, and postsurgical altered anatomy. ${ }^{13}$ Pancreatic ductal access and therapeutic intervention can be accomplished with a linear echoendoscope in many reports from expert centers. ${ }^{14-20}$ According to a report on EUS-guided $\mathrm{PD}$ drainage performed when retrograde access to the PD was technically unsuccessful because most of the patients underwent pancreatoduodenectomy, $64.7 \%$ of rendezvous procedures were successfully performed. ${ }^{21}$

\section{Roux-en-Y hepaticojejunostomy and end-to-side choledochojejunostomy}

Although choledochocholedochostomy is the preferred procedure, Roux-en-Y reconstruction (end-to-side choledochojejunostomy or hepaticojejunostomy) is performed in some cases of liver transplantation. Roux-en-Y reconstruction is often used in children and adults with bile duct disease such as sclerosing cholangitis. Hepaticojejunostomy is created with transection of the mid bile duct in most of the cases and if complication occurs in those situations, ERCP will not be possible with a standard duodenoscope. The only way to view the bilioenteric anastomosis in these cases is by passing a long endoscope (adult and pediatric colonoscope, SBE, or DBE) through the proximal jejunum and up the afferent jejunal limb. Variable stiffness pediatric colonoscope is the ideal en- 
doscope, with which searching for the anastomosis may take some experience, as it is frequently hidden behind a sharp turn or recessed fold. ${ }^{22}$ In a multicenter retrospective review of ERCP in postoperative patients, 12 patients who underwent Roux-en-Y hepaticojejunostomy had 100\% ERCP success rate with a pediatric colonoscope. ${ }^{23} \mathrm{~A}$ thorough understanding of a surgically altered anatomy is essential to minimize adverse events and to enhance the chance of a successful outcome in these cases.

\section{TECHNIQUES FOR THE BEST OUTCOMES}

ERCP and/or EUS are technically the most difficult procedure in endoscopic practice, and the most difficult situation is in cases of postoperative complications of an altered GI anatomy. Additional risk of perforation exists when endoscopic procedures are performed in postsurgical reconstructed anatomy. Careful preprocedural planning is mandatory in all cases to get successful outcomes. Before performing the procedure, understanding the postsurgical anatomy is important, and sometimes, checking operation reports, reviewing available radiologic images, and discussing with the surgeon to get clear information are required in complicated cases. Choice of the endoscope can only be made according to the endoscopist's understanding of the anatomic change and expertise. Selecting the suitable devices for the chosen endoscope is also important. A clear cap can be used to help in the visualization of pancreatic and/or biliary anastomoses in patients with a Whipple resection. Use of fluoroscopy may be helpful in identifying the pancreaticobiliary limb. Manual reshaping of accessories sometimes facilitate cannulation. Effort to minimize loop formation by applying external abdominal pressure or changing the patient's position, and maneuvers to straighten the endoscope are helpful to get the best outcomes. More detailed reviews about ERCP in post-gastrectomy and bilioenteric anastomosis, EUS in altered GI anatomy, and percutaneous transhepatic cholangioscopy in bilioenteric anastomotic strictures are included in the focused review series section of this issue of Clinical Endoscopy.

\section{CONCLUSIONS}

Owing to the relative safety and effectiveness for diagnosis and therapy for postoperative pancreaticobiliary complication with altered GI anatomy, endoscopic management would progressively replace reoperation and might become the treatment of choice in the near future. Careful preprocedural planning, including cautious review of operation reports and radiological images for complete understanding of postsurgi$\mathrm{cal}$ anatomic alteration, and multidisciplinary approach with close collaboration between gastroenterologists, surgeons, and interventional radiologist are needed for successful outcomes.

\section{Conflicts of Interest}

The authors have no financial conflicts of interest.

\section{REFERENCES}

1. Chahal P, Baron TH. ERCP for Acute and Chronic Adverse Events of Pancreatic Surgery and Pancreatic Trauma. In: Baron TH, Kozarek RA, Carr-Locke DL, eds. ERCP. 2nd ed. Philadelphia (PA): Elsevier; 2013. p. 402-409.

2. Bartoli FG, Arnone GB, Ravera G, Bachi V. Pancreatic fistula and relative mortality in malignant disease after pancreaticoduodenectomy. Review and statistical meta-analysis regarding 15 years of literature. Anticancer Res 1991;11:1831-1848.

3. House MG, Cameron JL, Schulick RD, et al. Incidence and outcome of biliary strictures after pancreaticoduodenectomy. Ann Surg 2006;243:571-576; discussion 576-578.

4. Wang AY, Sauer BG, Behm BW, et al. Single-balloon enteroscopy effectively enables diagnostic and therapeutic retrograde cholangiography in patients with surgically altered anatomy. Gastrointest Endosc 2010;71:641-649.

5. Navarrete C, Navarrete F, Gobelet JM, Valdivieso E, Muñoz-Navas M. Biliary Surgery Adverse Events Including Liver Transplantation. In: Baron TH, Kozarek RA, Carr-Locke DL, eds. ERCP. 2nd ed. Philadelphia (PA): Elsevier; 2013. p. 389-401.

6. Lee DW, Jo HH, Abdullah J, Kahaleh M. Endoscopic Management of Anastomotic Strictures after Liver Transplantation. Clin Endosc 2016;49:457-461.

7. Enestvedt BK, Kothari S, Pannala R, et al. Devices and techniques for ERCP in the surgically altered GI tract. Gastrointest Endosc 2016;83:1061-1075.

8. Chahal P, Baron TH, Topazian MD, Petersen BT, Levy MJ, Gostout CJ. Endoscopic retrograde cholangiopancreatography in post-Whipple patients. Endoscopy 2006;38:1241-1245.

9. Saleem A, Baron TH, Gostout CJ, et al. Endoscopic retrograde cholangiopancreatography using a single-balloon enteroscope in patients with altered Roux-en-Y anatomy. Endoscopy 2010;42:656-660.

10. Shimatani M, Matsushita M, Takaoka M, et al. Effective "short" double-balloon enteroscope for diagnostic and therapeutic ERCP in patients with altered gastrointestinal anatomy: a large case series. Endoscopy 2009;41:849-854.

11. Simmons DT, Baron TH, LeRoy A, Petersen BT. Percutaneous pancreatography for treatment of complicated pancreatic duct strictures. Pancreatology 2008;8:194-198.

12. Yamauchi FI, Ortega CD, Blasbalg R, Rocha MS, Jukemura J, Cerri GG. Multidetector CT evaluation of the postoperative pancreas. Radiographics 2012;32:743-764.

13. Chapman CG, Waxman I, Siddiqui UD. Endoscopic Ultrasound (EUS)-Guided Pancreatic Duct Drainage: The Basics of When and How to Perform EUS-Guided Pancreatic Duct Interventions. Clin Endosc 2016;49:161-167.

14. Kahaleh M, Hernandez AJ, Tokar J, Adams RB, Shami VM, Yeaton P. EUS-guided pancreaticogastrostomy: analysis of its efficacy to drain inaccessible pancreatic ducts. Gastrointest Endosc 2007;65:224-230.

15. François E, Kahaleh M, Giovannini M, Matos C, Devière J. EUS-guided pancreaticogastrostomy. Gastrointest Endosc 2002;56:128-133.

16. Kahaleh M, Yoshida C, Yeaton P. EUS antegrade pancreatography with gastropancreatic duct stent placement: Review of two cases. Gastrointest 
Endosc 2003;58:919-923.

17. Tessier G, Bories E, Arvanitakis M, et al. EUS-guided pancreatogastrostomy and pancreatobulbostomy for the treatment of pain in patients with pancreatic ductal dilatation inaccessible for transpapillary endoscopic therapy. Gastrointest Endosc 2007;65:233-241.

18. Bataille L, Deprez P. A new application for therapeutic EUS: main pancreatic duct drainage with a "pancreatic rendezvous technique". Gastrointest Endosc 2002;55:740-743.

19. Mallery S, Matlock J, Freeman ML. EUS-guided rendezvous drainage of obstructed biliary and pancreatic ducts: Report of 6 cases. Gastrointest Endosc 2004;59:100-107.

20. Sun C, Jin ZD, Pan X, Wang D, Li ZS. Endoscopic ultrasound-guided transgastric pancreatic duct drainage after Whipple surgery in a patient with chronic pancreatitis. Endoscopy 2011;43 Suppl 2 UCTN:E182-E183.

21. Kurihara T, Itoi T, Sofuni A, Itokawa F, Moriyasu F. Endoscopic ultrasonography-guided pancreatic duct drainage after failed endoscopic retrograde cholangiopancreatography in patients with malignant and benign pancreatic duct obstructions. Dig Endosc 2013;25 Suppl 2:109-116.

22. Lo SK. ERCP in Surgically Altered Anatomy. In: Baron TH, Kozarek RA, Carr-Locke DL, eds. ERCP. 2nd ed. Philadelphia (PA): Elsevier; 2013. p. 270-288.

23. Browne A, Kapoor S, Lewis AE, et al. A Multicenter Retrospective Review of Approach and Outcomes of Patients With Post-Surgical Anatomy Undergoing ERCP. Gastrointestinal Endoscopy;81(Suppl):AB412. 